\title{
COMUNICAÇÃO
}

\section{COBERTURA DO SOLO COM CAMA-DE-FRANGO, COM E SEM AMONTOA, NA PRODUÇÃO DE BETERRABA}

\author{
Soil covering with chicken manure, with and without hilling, on beetroot yield
}

\author{
Néstor Antonio Heredia Zárate ${ }^{1}$, Cleila Marcondes de Souza Sangalli², Maria do Carmo Vieira ${ }^{2}$, \\ João Dimas Graciano², Elaine Eva de Oliveira Munarin², Maria Fernanda dos Santos Paula²
}

\begin{abstract}
RESUMO
O trabalho foi desenvolvido no Horto de plantas medicinais da Universidade Federal da Grande Dourados-UFGD, em Dourados-MS. Foi avaliada a capacidade produtiva da beterraba (Beta vulgaris L.) 'Tall Top Early Wonder', cultivada em solo coberto com cama-de-frango (dose de $10 \mathrm{t} \mathrm{ha}^{-1}$ ) - CCF e sem cobertura com cama-de-frango semidecomposta - SCF e sem e com amontoa, em uma (21 dias após o transplante) e duas épocas ( 21 e 42 dias após o transplante). Os seis tratamentos foram arranjados como fatorial 2 x 3 , no delineamento experimental blocos casualizados, com seis repetições. As plantas CCF e com duas amontoas apresentaram a maior altura $(25,11 \mathrm{~cm})$ e superaram em $3,45 \mathrm{~cm}$ às CCF e sem amontoa, que tiveram menor altura. As maiores produções de massas frescas de folhas $\left(11,41 \mathrm{tha}^{-1}\right)$ e de raízes $\left(19,61 \mathrm{t} \mathrm{ha}^{-1}\right)$ foram das plantas CCF e com uma e duas amontoas, respectivamente e superaram em 5,21 t ha ${ }^{-1}$ e 9,12 $\mathrm{t} \mathrm{ha}^{-1}$, respectivamente, às das SCF com uma amontoa, que apresentaram as menores produções. As maiores percentagens de massas secas de folhas $(14,36 \%)$ e de raízes $(17,64 \%)$ foram das SCF e com uma amontoa, superando em $1,86 \%$ e $2,08 \%$, respectivamente, às das SCF com duas amontoas, que apresentaram as menores percentagens. A maior produção de massa fresca de raízes comerciais $\left(15,98 \mathrm{t} \mathrm{ha}^{-1}\right)$, a média por raiz $(129,30 \mathrm{~g})$ e o diâmetro médio da raiz $(68,93$ $\mathrm{mm}$ ), foram das plantas CCF e com duas amontoas. O maior comprimento médio das raízes comerciais $(64,48 \mathrm{~mm})$ foi das SCF com uma amontoa. As maiores renda bruta $(\mathrm{R} \$ 11.186,00)$ e renda líquida $(\mathrm{R} \$ 9.746,00)$ foram do tratamento CCF com duas amontoas, que superaram em $124,12 \%$ e $108,65 \%$, respectivamente, às do SCF e uma amontoa.
\end{abstract}

Termos para indexação: Beta vulgaris, tratos culturais, produtividade.

\begin{abstract}
This project was carried out at Medicinal Plant Garden of the Federal University of Grande Dourados - UFGD, in DouradosMS. Yield capacity of 'Tall Top Early Wonder' beetroot (Beta vulgaris L.) was evaluated when cultivated in soil covering with semidecomposed chicken manure (dose of $10 \mathrm{tha}^{-1}$ ) and without covering with chicken manure and with and without hilling, on one (21 days after transplant) and two dates ( 21 and 42 days after transplant). The six treatments were arranged in a $2 \times 3$ factorial scheme, in randomized block experimental design, with six replications. Plants cultivated using manure covering with two hillings showed greater height $(25.22 \mathrm{~cm})$ and were superior in $3.45 \mathrm{~cm}$ than those plants not using covering and without hilling, those of which showed lesser height. The highest production of fresh leaf mass $\left(11.41 \mathrm{t} \mathrm{ha}^{-1}\right)$ and of roots $\left(19.61 \mathrm{t} \mathrm{ha}^{-1}\right)$ were from plants using manure covering and one and two hillings, respectively, being superior in $5.21 \mathrm{t} \mathrm{ha}^{-1}$ and $9.12 \mathrm{t} \mathrm{ha}^{-1}$, respectively, than those without covering and with one hilling, that showed the smallest yield. The highest percentages of dried leaf mass $(14.36 \%)$ and of roots $(17.64 \%)$ were from plants without covering and with one hilling, which were superior in $1.86 \%$ and $2.08 \%$, respectively, than those plants without covering and with two hillings, those of which showed the smallest percentages. The highest yield of fresh mass of commercial roots $\left(15.98 \mathrm{t} \mathrm{ha}^{-1}\right)$, average per root $(129.30 \mathrm{~g})$ and average diameter per root $(68.93 \mathrm{~mm})$ were from plants using manure covering with two hillings. The greatest average length of commercial roots $(64.48 \mathrm{~mm})$ was from plants without manure covering and with one hilling. The greatest gross $(\mathrm{R} \$ 11,186.00)$ and net $(\mathrm{R} \$ 9,746.00)$ incomes were from plants that received manure covering treatment with two hillings, which were superior in $124.12 \%$ and $108.65 \%$, respectively, than those without manure covering and with one hilling treatment.
\end{abstract}

Index terms: Beta vulgaris, culture treatments, productivity.

(Recebido em 30 de julho de 2008 e aprovado em 13 de fevereiro de 2009)

A beterraba (Beta vulgaris L., Chenopodiaceae) é originária da Europa e a de mesa ou hortícola (Beta vulgaris L. var. crassa (Alef.) J. Helm) destaca-se, dentre as hortaliças, por sua composição nutricional, sobretudo em açúcares e ferro e pelas formas de consumo da raiz tuberosa e das folhas (Aquino et al., 2006). Fontes (2005) cita que, embora a raiz da

1Universidade Federal da Grande Dourados - Rua José Domingos Baldasso no 72 - Parque Alvorada - 79823-480 - Dourados, MS - nahz@terra.com.br 'Universidade Federal da Grande Dourados - Dourados, MS

Ciênc. agrotec., Lavras, v. 34, Edição Especial, p. 1598-1603, 2010 
beterraba seja mais consumida, as folhas são ricas em próvitamina A e ácido ascórbico, similares às do espinafre (Spinacia oleracea L.) e da acelga (Beta vulgaris L. var. cicla L.). O pigmento vermelho pode ser extraído e usado como corante natural e o sabor agradável deve-se ao teor de açúcares. A coloração intensa e uniforme, com o mínimo de zonas descoloridas, é importante fator de qualidade. As principais regiões produtoras de beterraba estão nos Estados de SãoPaulo, Minas Gerais e Rio Grande do Sul (Grangeiro et al., 2007). Camargo Filho \& Massei, citados por Trani et al. (2005), relatam que das 100.500 propriedades rurais produtoras de beterraba existentes no Brasil, $42 \%$ estão na Região Sul. No Estado de São Paulo, são cultivados 5.000 hectares, em média por ano.

Em Mato Grosso do Sul, há crescimento muito rápido da avicultura de corte e, na região da GrandeDourados há 430 aviários em produção e cada um produz cerca de $150 \mathrm{t} \mathrm{ano}^{-1}$ de cama-de-frango. Esse resíduo orgânico tem aumentado significativamente (Graciano, 2005) e poderia ser utilizado para melhorar as propriedades do solo e a produtividade de algumas culturas (Vieira, 1995; Graciano, 2005). Como a beterraba apresenta seu componente alimentar e comercializável se desenvolvendo sob a superfície do solo e os solos da região de Dourados são predominantemente Latossolos Roxos distroférricos de textura argilosa pesada, há necessidade de uso de resíduos orgânicos para melhorar a relação macro/ microporos, a capacidade de retenção de água e outros.

Nas últimas décadas, diversas técnicas foram incorporadas ao cultivo de hortaliças. Dessas, destaca-se a cobertura morta ou "mulching" que é a prática pela qual se aplica, como cobertura da superfície do solo, material orgânico ou inorgânico. As fontes mais comuns de resíduo orgânico são os resíduos de cultura, estercos e compostos. A escolha do resíduo vegetal a ser utilizado é função de sua disponibilidade, variando entre as regiões e com a cultura na qual se fará seu emprego (Heredia Zárate et al., 2004).

Dentre as práticas culturais utilizadas por produtores de algumas hortaliças, tem-se a amontoa, que consiste na movimentação de terra para cobrir parte da base do caule e/ou da raiz da planta (Heredia Zárate \& Vieira, 2005). Na literatura consultada, só foi encontrado o trabalho experimental de Terra et al. (2006) onde citam que, no milho doce 'Aruba', aos quinze dias após o semeio fezse a amontoa e concluíram que a amontoa foi dispensável.

Neste trabalho objetivou-se avaliar a capacidade produtiva das plantas de beterraba cultivadas em solo com e sem cobertura com cama-de-frango semidecomposta e sem e com uma e duas amontoas.
O trabalho foi desenvolvido em área do Horto de plantas medicinais da Universidade Federal da Grande Dourados-UFGD, em Dourados-MS, entre 14 de abril e 26 de agosto de 2007. O solo é do tipo Latossolo Vermelho distroférrico, de textura argilosa, com as seguintes características químicas: $\mathrm{pH}\left(\mathrm{CaCl}_{2}\right)=5,0 ; \mathrm{M} . \mathrm{O}=25,0 \mathrm{~g}$ $\mathrm{dm}^{-3} ; \mathrm{P}=23,0 \mathrm{mg} \mathrm{dm}^{-3} ; \mathrm{K}=195,5 \mathrm{mg} \mathrm{dm}^{-3} ; \mathrm{Ca}=4,1 \mathrm{cmol}_{\mathrm{c}}$ $\mathrm{dm}^{-3} ; \mathrm{Mg}=1,6 \mathrm{cmol}_{\mathrm{c}} \mathrm{dm}^{-3} ; \mathrm{Al}=0,06 \mathrm{cmol}_{\mathrm{c}} \mathrm{dm}^{-3} \mathrm{e} \mathrm{Al}+\mathrm{H}=$ $6,2 \mathrm{cmol}_{\mathrm{c}} \mathrm{dm}^{-3}$. Pela análise granulométrica, o solo era composto por $8 \%$ de areia grossa, $13 \%$ de areia fina, $16 \%$ de silte e $63 \%$ de argila. Dourados situa-se em latitude de $22^{\circ} 13^{\prime} 16^{\prime \prime} \mathrm{S}$, longitude de $54^{\circ} 17^{\prime} 01^{\prime \prime} \mathrm{W}$ e altitude de $430 \mathrm{~m}$. O clima da região, segundo a classificação de Köppen, é Mesotérmico Úmido; do tipo Cwa, com temperaturas e precipitações médias anuais, variando de $20^{\circ}$ a $24^{\circ} \mathrm{C}$ e 1250 a $1500 \mathrm{~mm}$, respectivamente.

Foi estudada a beterraba 'Tall Top Early Wonder', cultivada em solo sem e com cobertura com cama-de-frango semidecomposta (dose de $10 \mathrm{t} \mathrm{ha}^{-1}$ ) e sem e com uma, aos 21 dias após o transplante e duas amontoas, aos 21 e 42 dias, após o transplante. Os seis tratamentos foram arranjados como fatorial $2 \times 3$, no delineamento experimental blocos casualizados, com seis repetições. As parcelas tiveram área total de 2,25 $\mathrm{m}^{2}(1,5 \mathrm{~m}$ de comprimento $\mathrm{x} 1,5 \mathrm{~m}$ de largura) e área útil de $1,5 \mathrm{~m}^{2}$ (1,0 m de comprimento x 1,5 $\mathrm{m}$ de largura), contendo quatro fileiras de plantas espaçadas de 0,25 m e com 0,10 m entre plantas dentro das fileiras, perfazendo população de 264.000 plantas $\mathrm{ha}^{-1}$.

A propagação foi por mudas produzidas em bandejas plásticas com 162 células, preenchidas com substrato formado por substrato comercial, areia, terra e resíduo orgânico, nas proporções de 3:1:1:1. As sementes colocaram-se com 1 a $2 \mathrm{~cm}$ de profundidade. $\mathrm{O}$ solo foi preparado com aração, gradagem e levantamento de canteiros com rotoencanteirador. $\mathrm{O}$ transplante foi realizado quando as mudas apresentavam cerca de 5 folhas verdadeiras, com aproximadamente $10 \mathrm{~cm}$ de altura, o que aconteceu aos 28 dias após a semeadura. Após o transplante, realizou-se a cobertura do solo com a camade-frango, nas parcelas correspondentes para este tipo de tratamento. A análise química da cama-de-frango mostrou relação $\mathrm{C} / \mathrm{N}=10,99$ e teores de $\mathrm{C}_{\text {orgânico }}=205,6 \mathrm{~g} \mathrm{~kg}^{-1} ; \mathrm{P}_{\text {total }}$ $=28,5 \mathrm{~g} \mathrm{~kg}^{-1}, \mathrm{~K}_{\text {total }}=24,3 \mathrm{~g} \mathrm{~kg}^{-1} \mathrm{e} \mathrm{N}_{\text {total }}=18,7 \mathrm{~g} \mathrm{~kg}^{-1}$. Não foi realizada nenhuma forma de adubação. Para efetuar a amontoa, utilizaram-se enxadas, movimentando a terra para cobrir a base das raízes. As irrigações foram feitas por aspersão, com regas diárias, e o controle das plantas infestantes foi feito com enxadas, nas entre linhas e manualmente dentro das linhas. Não houve necessidade de controlar pragas e/ou doenças. 
A colheita foi realizada aos 106 dias após o transplante mediante o arranquio manual das plantas, utilizando-se como indicativo do ponto de colheita a perda de brilho e o início de senescência das folhas externas. Avaliaram-se a altura das plantas (desde o nível do solo até a curvatura da folha mais alta), a massa fresca das folhas (cortadas na altura do coleto), o diâmetro (na parte mais expandida da raiz) e o comprimento das raízes comerciais (desde o coleto até o final da parte reservante). Também foram determinadas as percentagens de massa fresca de raízes comerciais (raízes sadias acima de $30 \mathrm{~g}$ ) e de não-comerciais (raízes abaixo de $30 \mathrm{~g}$ e as rachadas).

As médias para cobertura, ou não, do solo com cama-de-frango foram testadas pelo teste $\mathrm{F}$, a $5 \%$ de probabilidades e, no caso da comparação das médias para as amontoas, utilizou-se o teste Tukey. A validação do trabalho foi realizada pela determinação da renda bruta e da renda líquida (renda bruta menos os custos referentes à cobertura do solo com cama-de-frango e das amontoas) por hectare. Para a determinação da renda bruta, foram pesquisados os preços pagos aos produtores de beterraba, dos arredores de Dourados, e depois foram efetuadas as conversões por hectare, pela multiplicação da produtividade média de cada tratamento pelo preço. Para determinar os custos da cobertura do solo considerou-se o custo da cama-de-frango $\left(\mathrm{R} \$ 40,00 \mathrm{t}^{-1}\right)+$ transporte $\left(\mathrm{R} \$ 15,00 \mathrm{t}^{-1}\right)+$ mão-de-obra para distribuição ao lanço $(\mathrm{R} \$$ $\left.25,00 \mathrm{t}^{-1}\right)=\mathrm{R} \$ 80,00$ por tonelada. $\mathrm{O}$ custo da mão-de-obra para cada amontoa foi considerado como sendo o dobro da utilizada para amontoa em milho superdoce (Terra et al., 2006), por tanto, foi de 16 dias/homem a R\$20,00 D/H.

Embora a altura das plantas não tenha sido influenciada significativamente pelos fatores em estudo
(Tabela 1), as plantas cultivadas em solo coberto com cama-de-frango-CCF e com duas amontoas apresentaram a maior altura $(25,11 \mathrm{~cm})$ e superaram em $3,45 \mathrm{~cm}$ à de menor altura, que foi das cultivadas em solo CCF e sem amontoa.

As massas frescas e secas de folhas e de raízes apresentaram efeito significativo da interação cobertura do solo e amontoas (Tabela 1). As maiores produções de massas frescas de folhas $\left(11,41 \mathrm{t} \mathrm{ha}^{-1}\right)$ e de raízes $\left(19,61 \mathrm{t} \mathrm{ha}^{-1}\right)$ foram obtidas nas plantas cultivadas em solo CCF e com uma e duas amontoas, respectivamente, e superaram em $5,21 \mathrm{t} \mathrm{ha}^{-1}$ e 9,12 $\mathrm{t} \mathrm{ha}^{-1}$, respectivamente, às das plantas cultivadas em solo SCF com uma amontoa, que apresentaram as menores produções. Segundo Vieira \& Casali (1997), os resíduos orgânicos poderão ter efeito benéfico se forem usados inclusive como cobertura do solo, especialmente nos solos de Cerrado muito intemperizados e com baixo teor de matéria orgânica, uma vez que são sujeitos ao aquecimento e dessecamento da camada superficial. A amontoa, segundo Heredia Zárate \& Vieira (2005), pode ter colaborado na destruição da crosta superficial no solo que diminui ou impede a infiltração lateral da água.

Em relação às maiores percentagens de massas secas de folhas $(14,36 \%)$ e de raízes $(17,64 \%)$, estas foram obtidas nas plantas cultivadas em solo SCF e com uma amontoa, superando em $1,86 \%$ e $2,08 \%$ as das plantas cultivadas em solo SCF com duas amontoas, que apresentaram as menores percentagens.

As massas frescas de raízes comerciais e não comerciais e o diâmetro e o comprimento de raízes comerciais de beterraba foram influenciadas significativamente pela interação cobertura do solo e amontoas (Tabela 2). A maior

Tabela 1 - Altura de plantas e massas frescas e secas de folhas e de raízes de beterraba, cultivadas em solo sem e com cobertura com cama-de-frango e sem ou com amontoas. UFGD, Dourados, 2007.

\begin{tabular}{|c|c|c|c|c|c|c|}
\hline \multicolumn{2}{|c|}{ Fatores em estudo } & \multirow{2}{*}{$\begin{array}{c}\text { Altura de } \\
\text { plantas } \\
(\mathrm{cm})\end{array}$} & \multicolumn{2}{|c|}{ Massa fresca $\left(\mathrm{t} \mathrm{ha}^{-1}\right)$} & \multicolumn{2}{|c|}{ Massa seca (\%) } \\
\hline $\begin{array}{c}\text { Cobertura } \\
\text { do solo }\end{array}$ & Amontoas & & Folhas & Raízes & Folhas & Raízes \\
\hline \multirow{3}{*}{ Com } & 0 & $21,66 \mathrm{a}$ & $7,47 \mathrm{~b}$ & $16,06 \mathrm{~b}$ & $13,58 \mathrm{a}$ & $16,42 \mathrm{a}$ \\
\hline & 1 & $23,47 \mathrm{a}$ & $11,41 \mathrm{a}$ & $17,08 \mathrm{~b}$ & $13,76 \mathrm{a}$ & $16,99 a$ \\
\hline & 2 & $25,11 \mathrm{a}$ & $9,57 \mathrm{ab}$ & $19,61 \mathrm{a}$ & $13,10 \mathrm{a}$ & $17,25 \mathrm{a}$ \\
\hline \multirow{3}{*}{ Sem } & 0 & $23,39 \mathrm{a}$ & $6,78 \mathrm{a}$ & $12,11 \mathrm{a}$ & $12,89 \mathrm{~b}$ & $17,14 \mathrm{a}$ \\
\hline & 1 & $22,02 \mathrm{a}$ & $6,21 \mathrm{a}$ & $10,49 \mathrm{a}$ & $14,36 \mathrm{a}$ & $17,64 \mathrm{a}$ \\
\hline & 2 & $22,25 \mathrm{a}$ & $6,94 \mathrm{a}$ & $12,18 \mathrm{a}$ & $12,50 \mathrm{~b}$ & $15,58 \mathrm{~b}$ \\
\hline \multicolumn{2}{|c|}{ C.V. (\%) } & 10,75 & 23,59 & 18,01 & 3,99 & 3,30 \\
\hline
\end{tabular}

Médias seguidas pelas mesmas letras, nas colunas, para amontoas dentro de cada tipo de cobertura do solo, não diferem pelo teste Tukey, a $5 \%$ de probabilidade.

Ciênc. agrotec., Lavras, v. 34, Edição Especial, p. 1598-1603, 2010 
produção de massa fresca de raízes comerciais por hectare $\left(15,98 \mathrm{t} \mathrm{ha}^{-1}\right)$, a massa média por raiz $(129,30 \mathrm{~g})$ e o diâmetro médio $(68,93 \mathrm{~mm})$, foram obtidas nas plantas cultivadas em solo CCF e com duas amontoas. O maior comprimento médio das raízes comerciais $(64,48 \mathrm{~mm})$ foi obtido nas plantas cultivadas em solo SCF com uma amontoa. Em relação às raízes não comerciais, as maiores produções foram das plantas cultivadas em solo CCF e com uma $\left(3,90 \mathrm{t} \mathrm{ha}^{-1}\right)$ ou duas $\left(3,63 \mathrm{tha}^{-1}\right)$ amontoas. A maior massa fresca média por raiz $(32,65 \mathrm{~g})$ correspondeu às plantas cultivadas em solo $\mathrm{CCF}$ e duas amontoas. Esses resultados sugerem que houve menor perda de água por evaporação induzida pela cobertura do solo (Carvalho et al., 2005) e aumento da quantidade de água e de nutrientes para o sistema radicular mais profundo, em razão da formação de um sulco entre as fileiras de plantas como efeito das amontoas.

Heredia Zárate et al. (2008), estudando quatro e cinco fileiras de plantas no canteiro e espaçamentos de 5,$0 ; 7,5$ e 10,0 cm entre plantas na produção e renda da beterraba 'Tall Top Early Wonder' observaram que as maiores produções de raízes comerciais foram de $15,70 \mathrm{t} \mathrm{ha}^{-1} \mathrm{e}$ 15,76 $\mathrm{t} \mathrm{ha}^{-1}$, respectivamente, no cultivo sob cinco fileiras no canteiro (média de 439.890 plantas ha ${ }^{-1}$, com espaçamento médio entre plantas de 7,5 cm) e 5,0 cm entre plantas (média de 594.000 plantas ha-1 ${ }^{-1}$ com número médio de 4,5 fileiras por canteiro). Sudo et al. (1997) estudando a beterraba
'Tall Top Early Wonder' em consorciação com a alface 'Regina 71', em cultivo orgânico, obtiveram raízes da beterraba com diâmetro médio de $5,7 \mathrm{~cm}$ e $5,6 \mathrm{~cm}$ sob monocultivo e consórcio, respectivamente. Esses valores diferentes dos obtidos neste experimento podem ter relação com as diferenças no sistema de cultivo utilizado.

As maiores renda bruta $(\mathrm{R} \$ 11.186,00)$ e líquida (R\$ 9.746,00) foi do tratamento solo CCF com duas amontoas que superaram em $124,12 \%$ e $108,65 \%$, respectivamente, às do tratamento solo SCF e uma amontoa (Tabela 3). Heredia Zárate et al. (2008), estudando número de fileiras no canteiro e espaçamentos entre plantas na produção e renda da beterraba 'Tall Top Early Wonder' observaram que a maior renda bruta $(\mathrm{R} \$ 6.700,00)$ foi do tratamento com cinco fileiras no canteiro e 5,0 cm entre plantas e a maior renda bruta menos o custo das sementes $(\mathrm{R} \$ 5.654,00)$ foi do tratamento cinco fileiras no canteiro e 10,0 cm entre plantas. Esses resultados divergentes mostram que a análise econômica, isto é, a determinação de alguns índices de resultado econômico, deve ser feita para se conhecer com mais detalhes a estrutura produtiva da atividade e se realizar as alterações necessárias ao aumento de sua eficiência (Perez Júnior et al., 2003).

Nas condições em que foi conduzido o experimento e considerando a renda líquida concluiu-se que, para a produção comercial da beterraba 'Tall Top Early Wonder', a cobertura do solo com cama-de-frango e com duas amontoas foram práticas culturais recomendáveis.

Tabela 2 - Massas frescas de raízes comerciais e não-comerciais e diâmetro e comprimento de raízes comerciais de raízes de beterraba, cultivadas em solo sem e com cobertura com cama-de-frango e sem ou com amontoas. UFGD, Dourados, 2007.

\begin{tabular}{|c|c|c|c|c|c|c|c|}
\hline \multicolumn{2}{|c|}{ Fatores em estudo } & \multicolumn{4}{|c|}{ Raízes comerciais } & \multirow{2}{*}{\multicolumn{2}{|c|}{$\frac{\text { Raízes não-comerciais }}{\text { Massa fresca }}$}} \\
\hline \multirow{2}{*}{$\begin{array}{c}\text { Cobertura } \\
\text { do solo }\end{array}$} & \multirow[t]{2}{*}{ Amontoas } & \multicolumn{2}{|c|}{ Massa fresca } & \multirow{2}{*}{$\begin{array}{c}\text { Diâmetro } \\
(\mathrm{mm})\end{array}$} & \multirow{2}{*}{$\begin{array}{l}\text { Compri- } \\
\text { mento } \\
(\mathrm{mm})\end{array}$} & & \\
\hline & & $\begin{array}{l}\text { Hectare } \\
\left(\mathrm{t} \mathrm{ha}^{-1}\right)\end{array}$ & $\begin{array}{l}\text { Média } \\
\left(\mathrm{g} \mathrm{raiz}^{-1}\right)\end{array}$ & & & $\begin{array}{c}\text { Hectare } \\
\left(\mathrm{t} \mathrm{ha}^{-1}\right)\end{array}$ & $\begin{array}{c}\text { Média } \\
\left(\mathrm{g} \mathrm{raiz}^{-1}\right)\end{array}$ \\
\hline \multirow{3}{*}{ Com } & 0 & $13,07 \mathrm{~b}$ & $100,50 \mathrm{~b}$ & $61,20 \mathrm{~b}$ & $61,50 \mathrm{a}$ & $2,99 \mathrm{~b}$ & $25,15 \mathrm{~b}$ \\
\hline & 1 & $13,18 \mathrm{ab}$ & $105,45 \mathrm{ab}$ & $66,35 \mathrm{a}$ & $62,35 \mathrm{a}$ & $3,90 \mathrm{a}$ & $29,48 \mathrm{ab}$ \\
\hline & 2 & $15,98 \mathrm{a}$ & $129,30 \mathrm{a}$ & $68,93 \mathrm{a}$ & $61,63 \mathrm{a}$ & $3,63 \mathrm{a}$ & $32,65 \mathrm{a}$ \\
\hline \multirow{3}{*}{ Sem } & 0 & $9,28 \mathrm{a}$ & $94,73 \mathrm{a}$ & $55,45 \mathrm{~b}$ & $55,45 \mathrm{~b}$ & $2,83 \mathrm{a}$ & $24,90 \mathrm{a}$ \\
\hline & 1 & $7,13 \mathrm{a}$ & 106,05 a & $60,18 \mathrm{a}$ & $64,48 \mathrm{a}$ & $3,36 \mathrm{a}$ & $25,80 \mathrm{a}$ \\
\hline & 2 & $8,84 \mathrm{a}$ & $88,48 \mathrm{a}$ & $60,45 \mathrm{a}$ & $59,75 \mathrm{~b}$ & $3,34 \mathrm{a}$ & $21,93 \mathrm{a}$ \\
\hline \multicolumn{2}{|c|}{ C.V. (\%) } & 23,20 & 14,21 & 5,08 & 3,91 & 9,28 & 14,49 \\
\hline
\end{tabular}

Médias seguidas pelas mesmas letras, nas colunas, para amontoas dentro de cada tipo de cobertura do solo, não diferem pelo teste Tukey, a $5 \%$ de probabilidade. 
Tabela 3 - Produção e renda bruta de raízes comerciais; custos da cama-de-frango, da amontoa e total e renda líquida de beterrabas, cultivadas em solo sem e com cobertura com cama-de-frango e sem ou com amontoas. UFGD, Dourados, 2007.

\begin{tabular}{|c|c|c|c|c|c|c|c|}
\hline \multicolumn{2}{|c|}{ Fatores em estudo } & \multicolumn{2}{|c|}{ Raízes comerciais } & \multicolumn{3}{|c|}{ Custos $(\mathrm{R} \$)^{2}$} & \multirow{2}{*}{$\begin{array}{l}\text { Renda líquida } \\
(\mathrm{R} \$)^{3}\end{array}$} \\
\hline $\begin{array}{c}\text { Cobertura } \\
\text { do solo }\end{array}$ & Amontoa & $\begin{array}{l}\text { Produção } \\
\left(\mathrm{t} \mathrm{ha}^{-1}\right)\end{array}$ & $\begin{array}{l}\text { Renda bruta } \\
\qquad(\mathrm{R} \$)^{1}\end{array}$ & $\begin{array}{l}\text { Cama-de- } \\
\text { frango }\end{array}$ & Amontoa & Total & \\
\hline \multirow{3}{*}{ Com } & 0 & 13,07 & $9.149,00$ & 800,00 & 0,00 & 800,00 & $8.349,00$ \\
\hline & 1 & 13,18 & $9.226,00$ & 800,00 & 320,00 & $1.120,00$ & $8.106,00$ \\
\hline & 2 & 15,98 & $11.186,00$ & 800,00 & 640,00 & $1.440,00$ & $9.746,00$ \\
\hline \multirow{3}{*}{ Sem } & 0 & 9,28 & $6.496,00$ & 0,00 & 0,00 & 0,00 & $6.496,00$ \\
\hline & 1 & 7,13 & $4.991,00$ & 0,00 & 320,00 & 320,00 & $4.671,00$ \\
\hline & 2 & 8,84 & $6.188,00$ & 0,00 & 640,00 & 640,00 & $5.548,00$ \\
\hline
\end{tabular}

${ }^{1}$ Preço pago ao produtor $=\mathrm{R} \$ 0,70 \mathrm{~kg}^{-1}$. Fonte: Vendedores de hortaliças no varejo em Dourados-MS, em 28-9-2007 (Comunicação pessoal). ${ }^{2}$ Custo da cama-de-frango + transporte + mão-de-obra para distribuição ao lanço $=\mathrm{R} \$ 80,00$ por tonelada.

Custo da mão-de-obra para cada amontoa $=16$ dias/homem a R\$ 20,00 D/H. Adaptado de Terra et al. (2006).

${ }^{3}$ Renda bruta - custo da cama-de-frango semidecomposta - mão-de-obra para cada amontoa.

\section{REFERÊNCIAS BIBLIOGRÁFICAS}

AQUINO, L.A.; PUIATTI, M.; PEREIRA, P.R.G.; PEREIRA, F.H.F.; LADEIRA, I.R.; CASTRO, M.R.S. Produtividade, qualidade e estado nutricional da beterraba de mesa em função de doses de nitrogênio. Horticultura Brasileira, Brasília, v.24, n.2, p.199-203, 2006.

CARVALHO, J.E.; ZANELLA, F.; MOTA, J.H.; LIMA, A.L.S. Cobertura morta do solo no cultivo de alface cv. Regina 2000, em Ji-Paraná/RO. Ciência e Agrotecnologia, Lavras, v.29, n.5, p.935-939, 2005.

FONTES, P.C.R. Olericultura: teoria e prática. Viçosa, MG: UFU, 2005. 486p.

GRACIANO, J.D. Arranjo de plantas e cobertura do solo com cama-de-frango na produção de dois clones de mandioquinha-salsa, em Dourados-MS. 2005. 50f. Tese (Doutorado em Agronomia)-Universidade Federal de Mato Grosso do Sul, Dourados, 2005.

GRANGEIRO, L.C.; NEGREIROS, M.Z.de; SOUZA, de B.S.; AZEVÊDO, P.E.de; OLIVEIRA, S.L.de; MEDEIROS, M.A.de. Acúmulo e exportação de nutrientes em beterraba. Ciência e Agrotecnologia, Lavras, v.31, n.2, p. 267-273, mar./abr., 2007.

HEREDIA ZÁRATE, N.A.; VIEIRA, M.C. Hortas: conhecimentos básicos. Dourados: UFMS, 2005. 61p.

HEREDIA ZÁRATE, N.A.; VIEIRA, M.C.; RECH, J.; GRACIANO, J.D.; GOMES, H.E.; PONTIM, B.C.A.
Número de fileiras no canteiro e espaçamento entre plantas na produção e rentabilidade da beterraba em Dourados, estado do Mato Grosso do Sul. Acta Scientiarum: Agronomy, Maringá, v.30, n.3, p.397-401, 2008.

HEREDIA ZÁRATE, N.A.; VIEIRA, M.C.; ROSA JÚNIOR, E.J.; SILVA, C.G. Forma de adição ao solo da cama-de-frango de corte semidecomposta para produção de taro. Pesquisa Agropecuária Tropical, Goiânia, v.34, n.2, p.111-117, 2004.

PEREZ JUNIOR, J.H.; OLIVEIRA, L.M.; COSTA, R.G. Gestão estratégica de custos. São Paulo: Atlas, 2003. $322 \mathrm{p}$.

SUDO, A.; GUERRA, J.G.M.; ALMEIDA, D.L. de; RIBEIRO, R. de L.D. Desempenho de alface (Lactuca sativa L.) e beterraba (Beta vulgaris L.) consorciados em sistema orgânico de produção. Horticultura Brasileira, Brasília, v.15, 1997. Suplemento. Resumo 309.

TERRA, E.R.; HEREDIA ZÁRATE, N.A.; VIEIRA, M.C.; MENDONÇA, P.S.M. Proposta de cálculo e forma de adubação, com e sem amontoa, para a produção e renda do milho Superdoce 'Aruba'. Acta Scientiarum:

Agronomy, Maringá, v.28, n.1, p.75-82, 2006.

TRANI, P.E.; CANTARELLA, H.; TIVELLI, S.W. Produtividade de beterraba em função de doses de sulfato de amônio em cobertura. Horticultura Brasileira, Brasília, v.23, n.3, p.726-730, 2005. 
VIEIRA, M.C. Avaliação do crescimento, da produção de clones e efeito de resíduo orgânico e de fósforo em mandioquinha-salsa no Estado de Mato Grosso do Sul. 1995. 146f. Tese (Doutorado em Fitotecnia)-Universidade Federal de Viçosa, Viçosa, 1995.

VIEIRA, M.C.; CASALI, V.W.D. Adaptação da cultura da mandioquinha-salsa à adubação orgânica. Informe Agropecuário, Belo Horizonte, v.19, n.190, p.40-42, 1997.

de fileiras no canteiro e espaçamento entre plantas na produção e rentabilidade da beterraba em Dourados, estado do Mato Grosso do Sul. Acta Scientiarum: Agronomy, Maringá, v.30, n.3, p.397-401, 2008.

HEREDIA ZÁRATE, N.A.; VIEIRA, M.C.; ROSA JÚNIOR, E.J.; SILVA, C.G. Forma de adição ao solo da cama-de-frango de corte semidecomposta para produção de taro. Pesquisa Agropecuária Tropical, Goiânia, v.34, n.2, p.111-117, 2004.

PEREZ JUNIOR, J.H.; OLIVEIRA, L.M.; COSTA, R.G.

Gestão estratégica de custos. São Paulo: Atlas, 2003. 322p.
SUDO, A.; GUERRA, J.G.M.; ALMEIDA, D.L. de; RIBEIRO, R. de L.D. Desempenho de alface (Lactuca sativa L.) e beterraba (Beta vulgaris L.) consorciados em sistema orgânico de produção. Horticultura Brasileira, Brasília, v.15, 1997. Suplemento. Resumo 309.

TERRA, E.R.; HEREDIA ZÁRATE, N.A.; VIEIRA, M.C.; MENDONÇA, P.S.M. Proposta de cálculo e forma de adubação, com e sem amontoa, para a produção e renda do milho Superdoce 'Aruba'. Acta Scientiarum: Agronomy, Maringá, v.28, n.1, p.75-82, 2006.

TRANI, P.E.; CANTARELLA, H.; TIVELLI, S.W. Produtividade de beterraba em função de doses de sulfato de amônio em cobertura. Horticultura Brasileira, Brasília, v.23, n.3, p.726-730, 2005.

VIEIRA, M.C. Avaliação do crescimento, da produção de clones e efeito de resíduo orgânico e de fósforo em mandioquinha-salsa no Estado de Mato Grosso do Sul. 